\title{
The estimation of streptomycin- nonspecific effect on Baikal endemic amphipods Eulimnogammarus verrucosus
}

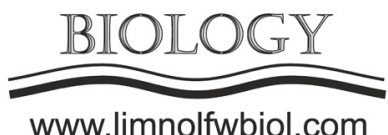

\author{
Zolotovskaya E.D.*, Axenov-Gribanov D.V., Timofeyev M.A. \\ Irkutsk State University, K. Marx str., 1, Irkutsk, 664003, Russia
}

ABSTRACT. In this study, we demonstrated the estimation of model antibiotic on Baikal endemic amphipods. The results showed the influence of streptomycin on crustaceans symbiotic microflora and season-dependent stress-reaction connected with glutathione S-transferase activity change.

Keywords: Lake Baikal, amphipods, glutathione S-transferase, streptomycin

Lake Baikal is a unique ancient ecosystem with a high diversity of endemic species, and with a stable hydrochemical composition of water. The order Amphipoda is one of the groups which get a wide diversity in the lake (Bazikalova, 1945). Crustaceans are widespread animals in Lake Baikal, and therefore can be subjected to the effect of various xenobiotics or drugs which can get into the water with wastewater of agricultural enterprises or with human waste (Timoshkin et al., 2016; Ebele et al., 2017; Danner et al., 2019). However, the drug and antibiotic in particular influence on ecosystem inhabitants still unknown.

Thus, the current study was aimed to estimate the nonspecific effects of streptomycin on Baikal endemic amphipods Eulimnogammarus verrucosus (Gerstfeld, 1858).

The amphipods were collected in the littoral zone of Lake Baikal near Listvyanka village. The acclimation of animals was carried out to laboratory conditions for 4 days at the temperature of $6{ }^{\circ} \mathrm{C}$ in well-aerated aquaria.
This study consists of two stages. At the first stage, we estimated the long-term antibiotic influence on amphipods survival. Here amphipods were kept during 4 days in aquaria containing Baikal water with streptomycin solution in a final concentration of $7.5 \mathrm{mg}$ / $\mathrm{L}$ and $15 \mathrm{mg} / \mathrm{L}$. At the second stage we estimated a short-term antibiotic influence on the activity of glutathione S-transferase (GST). GST is an antioxidant system enzyme, which responsible for removing xenobiotics from the organism. In this experiment, amphipods were exposed in Baikal water with streptomycin solution with the same concentrations. After 6 hours, amphipods were transferred for recovery into clean Baikal water. We had measured the dynamic of GST activity, after fixation of samples. The statistical data analysis was performed using software PAST3.

The results of experiments showed that the antibiotic effect during 4 days does not lead to mortality of amphipods. Materials presented on Figure 1 presented a decrease of activity trend of GST after exposure in both concentrations of streptomycin
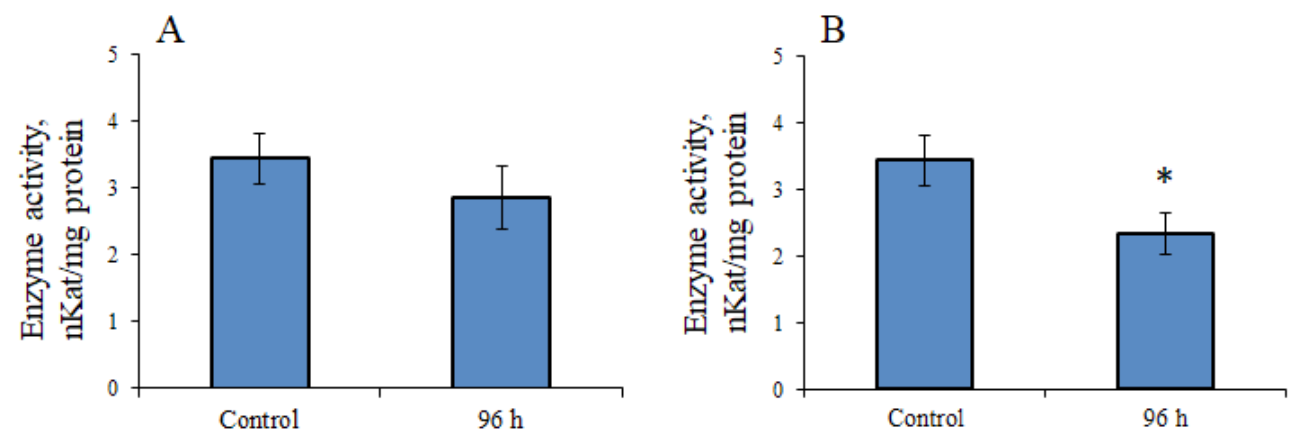

Fig.1. The change of glutathione S-transferase activity during the exposure of $E$. verrucosus in concentrations of streptomycin at $7.5 \mathrm{mg} / \mathrm{L}(\mathrm{A})$ and $15 \mathrm{mg} / \mathrm{L}(\mathrm{B})$.

* - indicates significant difference $(\mathrm{p}<0.05)$.

*Corresponding author.

E-mail address: zolotovskayaelenad@gmail.com (E. D. Zolotovskaya)
(C) Author(s) 2020. This work is distributed under the Creative Commons Attribution 4.0 License. 


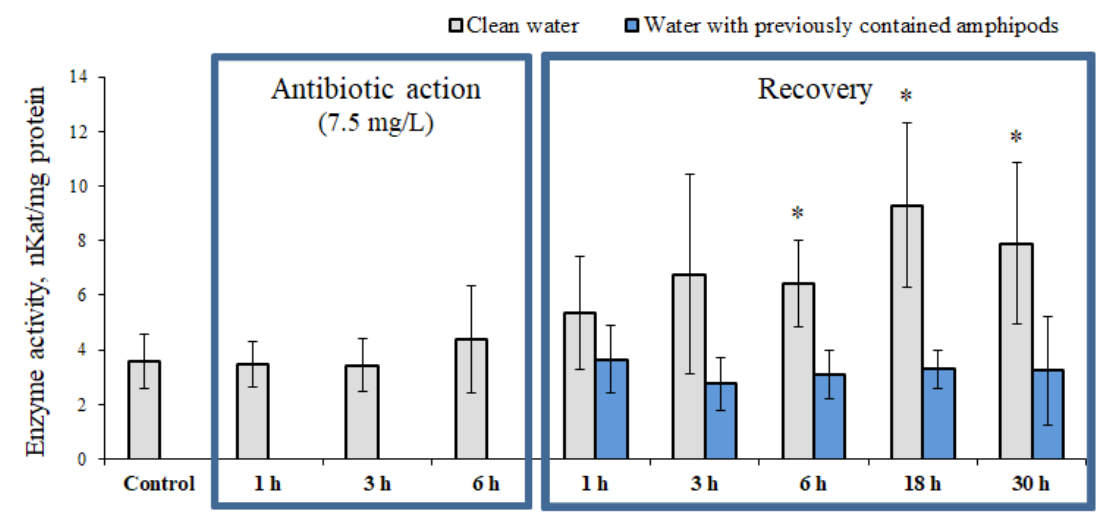

Fig.2. The change of glutathione S-transferase activity in the wintertime, during the exposure of $E$. verrucosus in concentrations of streptomycin $7.5 \mathrm{mg} / \mathrm{L}$.

* - indicate significant difference $(\mathrm{p}<0.05)$.
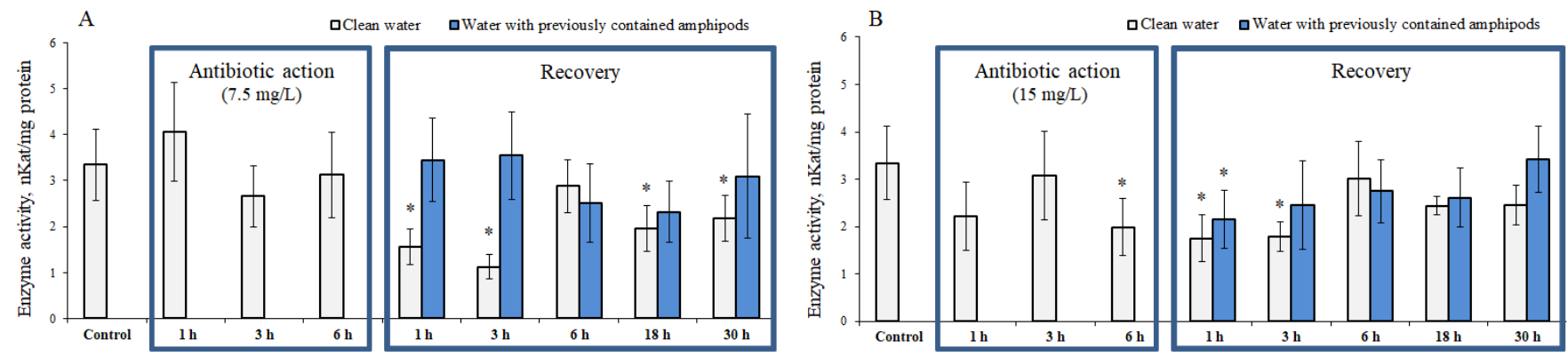

Fig.3. The change of glutathione S-transferase activity in the summertime, during the exposure of E. verrucosus in concentrations of streptomycin $7.5 \mathrm{mg} / \mathrm{L}(\mathrm{A})$ and $15 \mathrm{mg} / \mathrm{L}(\mathrm{B})$.

* - indicates significant difference $(\mathrm{p}<0.05)$.

(7.5 and $15 \mathrm{mg} / \mathrm{L}$ ). However, after exposure to a streptomycin solution with a concentration of $15 \mathrm{mg}$ / $\mathrm{L}$, there was a statistically significant decrease in enzyme activity (Fig. 1B).

During short-term antibiotic exposure experiments with a water change, we demonstrated, that transferring of amphipods to water with previously contained amphipods, does not affect the change in GST activity. On the contrary, the transfer of amphipods in clean water leads to change in the activity of an enzyme (Fig. 2).

Besides, we found that the effect of the antibiotic on amphipods is season-depended. Thus, for amphipods that were collected in the wintertime, we detected a trend to increased activity of GST after transferring them into clean water (Fig. 2). In amphipods that were collected in the summertime, we detected a trend to decreased activity of the enzyme (Fig.3A). However, we did not detect changes in GST activity after transferring animals into the water where amphipods were previously exposed. We assume that such water may contain symbiotic microorganisms and can enter from crustaceans into the environment. Twofold increase concentration of antibiotic $(15 \mathrm{mg} / \mathrm{L})$ showed the same results (Fig. 3B).
Thus, we demonstrated, that antibiotic can affect symbiotic microflora of amphipods and cause dysbiosis, which should be considered during experiments.

The study was carried out with the main financial support of the grant of Russian Foundation for Basic Research (18-29-05051), and Ministry of Education and Science of Russian Federation (FZZE-2020-002).

\section{References}

Bazikalova A.Y. 1945. Amphipods of Lake Baikal. Trudy Baikalskoi Limnologicheskoi Stantsii [Proceedings of Baikal Limnological Station] 11: 1-440. (in Russian)

Danner M.C., Robertson A., Behrends V. et al. 2019. Antibiotic pollution in surface fresh waters: occurrence and effects. Science of the Total Environment 664: 793-804. DOI: 10.1016/j.scitotenv.2019.01.406

Ebele A.J., Abdallah M.A.E., Harrad S. 2017. Pharmaceuticals and personal care products (PPCPs) in the freshwater aquatic environment. Emerging Contaminants 3: 1-16. DOI: 10.1016/j.emcon.2016.12.004

Timoshkin O.A., Samsonov D.P., Yamamuro M. et al. 2016. Rapid ecological change in the coastal zone of Lake Baikal (East Siberia): Is the site of the world's greatest freshwater biodiversity in danger? Journal of Great Lakes Research 42: 487-497. DOI: 10.1016/j.jglr.2016.02.011 